\title{
IMSTeP : Indonesian Marine Science And Techno Park Implementasi Kebijakan Model Van Meter Dan Van Horn Di Indonesia
}

\author{
Riki Kurniawan, M.Benny Alexandri, dan Heru Nurasa \\ Master of Public Policy, Faculty of Social and Political Sciences, \\ Universitas Padjadjaran, Bandung, Indonesia \\ riki.s2unpad@gmail.com ${ }^{1}$ \\ bennyalexandri@yahoo.co.id ${ }^{2}$ \\ heru.nurasa@unpad.ac.id ${ }^{3}$
}

\begin{abstract}
The marine resources are waiting for the nation's explorer. Government support and past glory should be a giant step to develop real marine sector support programs. The nations assets supporting facilities and infrastructure of maritime science and technology sector is important to be considered for the efficiency of cost and expenditure of state and the progress of science and technology in the field of Marine.Pra feasibility that has been done, after the formation of Team Work and the support from central government collaboration across Ministries and Research Institutions, also supported by government readiness areas within the development of the Indonesia Marine Science and Technology Center (IMSTeP) should be a solid and well-maintained cooperation. The policy issued by the government is required to be able to cover every progress. However whether the policy can be implemented well operationally and substansinya or still need support derivative policies or other bureaucratic obstacles that need to be anticipated to accelerate the progress of this national program so that we soon become Master in his own country in the inner sector in particular ,,,, JalesvevaJayamahe.
\end{abstract}

Keywords: policy implentation,nawacita, marine, science park.stakeholder

\begin{abstract}
Abstrak
Sumberdaya kelautan yang berlimpah menunggu para explorer anak bangsa untuk bergerak. Dukungan Pemerintah dan kejayaan masa lalu seharusnya menjadi cermin untuk mengembangkan program riil pendukung sektor kelautan khususnya. Aset pendukung sarana dan prasarana iptek sektor kelautan penting untuk diperhatikan demi efisiensi cost dan pengeluaran negara serta kemajuan Iptek di bidang Kelautan.Pra feasibility yang sudah dilakukan, setelah pembentukan Tim Pokja serta dukungan kolaborasi pemerintah pusat lintas Kementerian dan Lembaga Penelitian, di dukung oleh kesiapan pemerintah daerah didalam pengembangan Pusat Iptek Kelautan (IMSTeP) harus menjadi satu kerjasama yang solid dan terpelihara. Kebijakan yang dikeluarkan pemerintah dituntut mampu memayungi setiap progress kemajuannya.Namun apakah kebijakan tersebut dapat terimplementasikan dengan baik secara operasional dan substansinya atau masih perlukah dukungan kebijakan turunannya atau kendala birokrasi lain yang perlu segera di antisipasi untuk mempercepat progress progam nasional ini sehingga dengan segera kita menjadi Tuan di Negeri Sendiri di sektor keluatan khususnya,,,, JalesvevaJayamahe.
\end{abstract}

Kata kunci: implementasi kebijakan,nawacita,kelautan,iptek,stakeholder.

\section{LATAR BELAKANG}

Penguasaan Ilmu Pengetahuan (Iptek) sumber daya alam kelautan yang berlimpah di negara kepulaun terbesar ini dengan garis pantai $99.000 \mathrm{~km}$ dan luas lautan 2juta km2 masih kurang maksimal. Potensi sumberdaya keluatan mulai di permukaan sampai dibawah dasar laut menunggu untuk di ekploitasi secara cerdas dan berkesinambungan oleh anak anak bangsa Indonesia. 


\section{Gambar 1. Diagram Potensi Ekonomi}

\section{Potensi Ekonomi Maritim Harus Lebih Dioptimalkan}

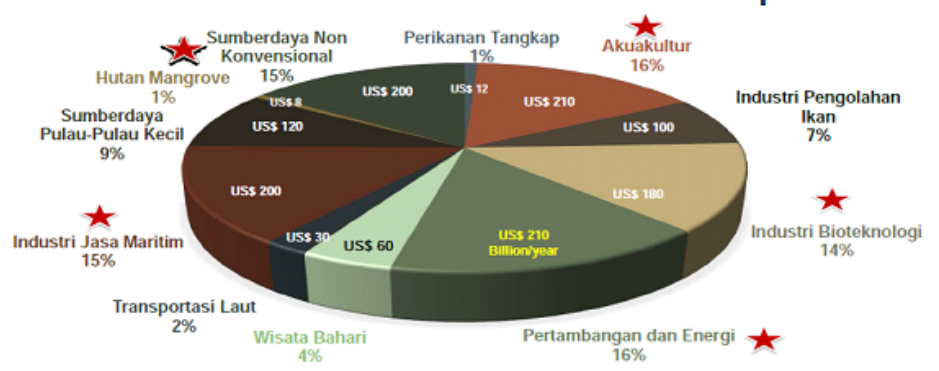

Potensi Ekonomi Maritim Indonesia US\$ 1,33 triliun per tahun

Sumber : Paparan Kemenko m tanggal 17 oktober 2017 hal 4

Dukungan Iptek kelautan ini tersebar di berbagai institusi dengan program dan fokus masing masing. 12 kapal riset lebih dan fasilitas penelitian dan pengembangan(litbang) tersebar di wilayah dari sabang sampai merauke. Namun keberadaan fasilitas tersebut kurang mendapat perhatian didalam operasional dan manajemennya. Salah satu sarana dan prasarana (sarpras) semisal sandar labuh kapal riset hanya ada beberapa lokasi di seluruh Indonesia, belum lagi bicara luasnya cakupan operasionalisasi kapal kapal riset tersebut. Sehingga diperlukan suatu Pusat Manajemen yang menangani khusus sarpras iptek kelautan. Kemenristekdikti telah memfasilitasi kajian untuk keperluan tersebut yang tertuang di dalam laporan pra Feasibility Studi Indonesia Marine Scince and Techno Park (IMSTeP) di Kabupaten Penajam Paser Utara (PPU), Kalimantan Timur.

Stakeholder di pusat dan di daerah dilibatkan didalam setiap langkah kemajuan program dari rencana pembangunan IMSTeP ini. Sejak tahun 2014, Kementerian Koordinator Maritim (Kemenko Maritim) langsung menjadikan program IMSTeP ini menjadi salah satu agenda penting dan BPPT/Baruna Jaya menjadi key leader untuk tim kelompok kerja (Pokja) untuk melaksanakan program ini selanjutnya.(Sumber Hasil Rapat Stakeholder Tanggal 15 Januari 2015 di Gedung Kemenko Maritim Jakarta.

Gambar 2. Milestone Momen Penting

\section{Peristiwa Penting Perkembangan Indonesia sebagai Negara Maritim}

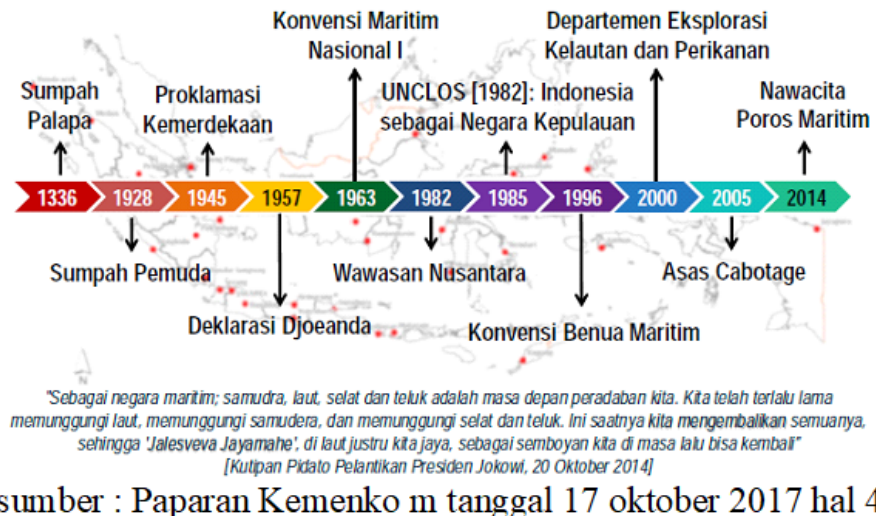


Kebijakan pendukung program ini yang tertuang dalam UUD 45, undang undang kelutan no 32 tahun 2014 tentang Kelauatan menjadi payung kebijakan bagi masing masing stakeholder untuk bergerak mendukung, namun sejalan waktu, pergerakan menuju tujuan program ini dirasa lambat bahkan stagnan.

Apakah implementasi dari kebijakan yang ada kurang menjadi landasan pergerakan tim pokja ataukah ada kendala kebijakan yang menghambat progress dari program ini.

\section{METODE PENELITIAN}

Dalam penyusunan penelitian tentang implentasi kebijakan ini menggunakan metode kualifikasi dalam rangka menghasilkan suatu rekomendasi melalui data sekunder di media elektronik serta jurnal jurnal ilmiah lewat studi literature Systematic Mapping Study (SMS) dan Systematic Literature Review (SLR) dan pengolahan data primer hasil inventarisir data terkini(laporan kajian), hasil rapat / FGD serta wawancara didalam memperkaya hasil analisa dan evaluasi Implementasi Kebijakan dengan model Van Meter Van Horn.

Metode penelitian Systematic mapping study (SMS) sendiri merupakan bagian dari systematic literature review (SLR) karena SMS merupakan tahap awal sebelum melakukan SLR (Kitchenham \& Charters, 2007; Petersen et al., 2009). Ada dua point yang melandasi dilakukannya SLR dalam penelitian ini. Pertama, teori Pittaway et al. (2008) yang menyatakan bahwa SLR dalam penelitian ini berguna untuk mengurangi fragmentasi. Kedua, teori Hindle (2007) yang mengemukakan bahwa dalam konteks koalisi ada beberapa fenomena namun konsistensinya perlu dijaga. Namun SLR menurut Thorpe et al. (2005) sebaiknya tetap memenuhi prinsip dasar, yaitu transparan, jelas, fokus dan seragam. Dalam analisa implentasi kebijakannya peneliti mengaplikasikan model pendekatan implementasi kebijakan yang dirumuskan Van Meter dan Van Horn yang disebut dengan A Model of the Policy Implementation (1975). Proses analisa implementasi ini merupakan sebuah abstraksi atau performansi suatu pengejewantahan kebijakan yang pada dasarnya dilakukan untuk meraih kinerja implementasi kebijakan yang tinggi yang berlangsung dalam hubungan berbagai variabel. Model ini mengandaikan bahwa implementasi kebijakan berjalan secara linear dari keputusan politik, pelaksana dan kinerja kebijakan publik. Model ini menjelaskan bahwa kinerja kebijakan dipengaruhi oleh beberapa variabel yang saling berkaitan, variable-variabel tersebut yaitu:

1. Standar dan sasaran kebijakan/ukuran dan tujuan kebijakan

2. Sumber daya

3. Karakteristik organisasi pelaksana

4. Sikap para pelaksana
5. Komunikasi antar organisasi terkait dan kegiatan-kegiatan pelaksanaan

6. Lingkungan sosial, ekonomi dan politik

Dalam buku Ripley dan Franklin yang berjudul Birokrasi dan Implementasi Kebijakan (Policy Implementation and Bureaucracy) menyatakan bahwa keberhasilan implementasi kebijakan atau program dapat ditujukan dari tiga faktor yaitu :

1. Perspektif kepatuhan (compliance) yang mengukur implementasi dari kepatuhan strect level bereau crats terhadap atasan mereka.

2. Keberhasilan implementasi diukur dari kelancaran rutinitas dan tiadanya persoalan.

3. Implementasi yang berhasil mengarah kepada kinerja yang memuaskan semua pihak terutama kelompok penerima manfaat yang diharapkan”. (Ripley dan Franklin, 1986:89)

Secara sederhana ketiga faktor diatas merupakan suatu kepastian dalam menilai keberhasilan suatu implementasi kebijakan sehingga kurang hilangnya salah satu faktor mempengaruhi sekali terhadap kinerja kebijakan tersebut.

Namun sebaliknya Jam Marse menyatakan bahwa ada tiga faktor yang dapat menimbulkan kegagalan dalam implementasi kebijakan yaitu:

1. Isu kebijakan. Implementasi kebijakan dapat gagal karena masih ketidaktetapan atau ketidak tegasan intern maupun ekstern atau kebijakan itu sendiri, menunjukan adanya kekurangan yang menyangkut sumber daya pembantu.

2. Informasi. Kekurangan informasi dengan mudah mengakibatkan adanya gambaran yang kurang tepat baik kepada objek kebijakan maupun kepada para pelaksana dari isi kebijakan yang akan dilaksanakannya dan hasil-hasil dari kebijakan itu.

3. Dukungan. Implementasi kebijakan publik akan sangat sulit bila pada pelaksanaanya tidak cukup dukungan untuk kebijakan tersebut.

(Solichin, 1997:19)

\section{PENELITIAN TERKAIT}

Konsep yang dibangun terkait pengertian luas IMSTeP merupakan suatu hasil kajian pokja masterplan yang didalamnya terintegrasi semua kebutuhan stakehoder baik secara operasional maupun fasilitas non teknis di daratnya, lebih dari pada pengertian scince centre saat ini (Saba Siddiki, 2014), manajemen kelembagaan pengelolaan kawasan akan bersifat profit centre dan mixed management antara pemerinrah dan swasta. Payung regulasi akan bersifat nasional dan melibatkan multi pakar didalam pengembangan kebijakannya dan pembangunan fisik ke depannya.

Terkait dengan analisa implementasi yang dilakukan menggunakan model van meter van horn, ada 6 varibel yang saling berkaitan. Peneliti mencoba mengaitkan penelitian yang pernah dilakukan sebelumnya untuk 
menguatkan deskripsi didalam menganalisa tiap tiap variabel melalui jurnal jurnal yang sesuai dengan variabel yang dimaksud dan dalam implemntasi suatu kebijakannya harus didukung publik atau stakeheolder (Anne Rasmussen, 2018) artinya keberhasilan implementasi kebijakan program pengembangan IMSTeP ini harus didukung oleh stakeholder mulai dari pusat, daerah dan luar negeri. Antisipasi kendala komunikasi sejak awal harus bisa diantisipasi semisal dinatar pengelola keuangan ((Rosmery Elsye,2014). Pemerintah Kabupaten PPU dan Pemerintah Provinsi Kaltim harus merespon positif setiap kebijakan bersama dan mendukung secara konkret semisal sharing cost dan dan partsisipasi masyarakat pun sangat di harapkan (Asna Aneta,2010)

Ke depannya pun hasil hasil riset sektor kelautan harus lebih serius mendukung semua aspek fundamental didalam penelitian.Bukan hanya gap teori dan praktek namun gap antara kebutuhan publik/ industri dan bagimana menghubungkannya (B. Dana Kivel,2018) .

\section{HASIL DAN DISKUSI}

\subsection{Standar dan Sasaran Kebijakan/Ukuran dan Tujuan Kebijakan}

Hasil Tim Pokja yang sudah berjalan sampai saat ini perlu dukungan dukungan kebijakan yang terintegrasi dan sinergi dari pusat (termasuk dilingkungan internal $\mathrm{K} / \mathrm{L}$ ), kemitraan dengan luar negeri sampai daerah sebagai tuan rumah di mana fisik proyek itu berada.

Kebijakan pemerintah untuk bisa terus menggerakkan program tersebut membutuhkan terobosan dan pembobotan dalam kebijakan yang disusun menyertakan peran semua stakeholder. Transparansi anggaran dan kebijakan teknis salah satu tools stakeholder.

4.2. Sumber Daya

Skala internasional dimensi implentasi kebijakan pembangunan IMSTeP menuntut sumber daya manusia, sumber daya anggaran dan sumber daya kebijakan yang luar biasa sehingga diperlukan suatu materi penguasaan yang baik. Khususnya kebijakan hubungan dengan luar negeri.

\subsection{Karakteristik Organisasi Pelaksana}

Seperti diuraikan di point sebelumnya , sejalan dengan dimensi internasional objek ini, maka pengembangan dan karakter organisasinya harus mampu beradaptasi dengan lingkungan dan perkembangn iptek di dunia bahkan jika bisa mampu menjadi leader di bidang kelautan.

4.4. Komunikasi Antar Organisasi Terkait dan Kegiatan-Kegiatan Pelaksanaan Sikap

Sinergi dan kolaborasi aktif baik internal dan eksternal stakeholder nasional ini diharapkan juga di dukung secara sinergi oleh eksekutif pemerintah di pusat dan di daerah.

4.5. Disposisi atau Sikap Para Pelaksana
Terkait erat dengan point 4.4, keterlibatan stakeholder dalam implementasi kebijakan ini seyogyanya sejak awal dilibatkan didalam merumuskan kebijakan dipusat dan turunannya di daerah sehingga kondisi fluktuatif dilapangan dapat di redam dan ada jalan keluarnya. Visi pemimpin daerah harus tetap selaras dengan program sebelumnya dan kan datang terkait pembangunan IMSTeP ini.

4.6. Lingkungan Sosial, Ekonomi dan Politik

Dalam variable ini peran media, permasalahan sosial dan singgungan politik harus bisa di redam melalui kebijakan dari pusat sampai di kebijakan di daerah .Serta perlunya design suatu kawasan yang berimbang sesuai dengan hukum nasional dan internasioan mengingat skala peruntukan IMSTeP ini yang menjadi host bagi kemajuan Iptek Internasioan di sektor kelautan

\section{KESIMPULAN}

Dengan dihasilkannya analisa terhadap data dan fenomena yang ada, diharapkan pemerintah melakukan upaya yang lebih konkret dan komprehensif terhadap permasalahan dukungan kebijakan turunan yang di peruntukan di masing masing internal $\mathrm{K} / \mathrm{L}$ serta di level lintas K/L dan hubungan dengan pihak luar negeri. Hal lain yang harus segera di tindaklanjuti adalah statement tertulis atau legal draft komitmen kepastian fokus dan lokus dari objek program IMSTeP ini. Selanjutnya rekomendasi kebijakan yang akan dikeluarkan harus di dukung oleh Pemerintah Daerah, Pusat dan pihak luar negeri

\section{REFERENSI}

Akib, Haedar, 2010, Implementasi Kebijakan: Apa, Mengapa, Dan Bagaimana ,Jurnal Administrasi Publik, Volume 1 No. 1 Thn. 2010

Anderson, James E, 1994. Public Policy Making - An Introduction (second edition), Texas A \& $\mathrm{M}$ University

Aneta, Asna,2010, Implementasi Kebijakan Program PenanggulanganKemiskinan Perkotaan (P2kp) Di Kota Gorontalo, Jurnal Administrasi Publik, Volume 1 No. 1 Thn. 2010

Dunn, William N., 1999, Analisis Kebijakan Publik, Yogjakarta: Gadjah Mada University Press.

Dye, Thomas R., 1995, Understanding Public Policy, New Jersey: Prentice Hall.

Kivel,B. Dana,2018,Are We Ready for "Radical Leisure”?,routledge

Laporan Kajian Puspiptekla, 2014. Kementerian Riset, Teknologi dan Pendidikan Tinggi

Meter, Donald Van, dan Carl Van Horn, 1975, "The Policy Implementation Process: A Conceptual Framework dalam Administration and Society 6, 1975, London: Sage. 
Nugroho D, Riant, 2005. Kebijakan Publik : Formulasi, Implementasi dan Evaluasi. Jakarta : PT. Elex Media Komputindo

Peraturan Presiden Nomor 10 thn 2015 Tugas Kemenko Maritim

Peraturan Presiden Nomor 16 Tahun 2017, Tentang 7 Pilar KebijakanKelautan Indonesia

Peraturan Presiden Republik Indonesia, Nomor 16 tahun 2017, Tentang Kebijakan Keluatan Indonesia

Rasmuseen, Anne dkk,2017,With a Little Help From The People? The Role of Public Opinion in Advocacy Success

Siddiki, Saba dan Goel, Shilpi, 2015, A stakeholder analysis of U.S.marine aqua culture partnerships ,Elsevier

Undang Undang Republik Indonesia, Nomor 32 Tahun 2014 , Tentang Kelautan

Undang-Undang Dasar 1945

Winarno, Budi. 2002. Teori dan Proses kebijakan Publik. Yogyakarta: Media Pressindo. Wahab, Solichin A. 2008. Pengantar Analisis Kebijakan Publik. Malang : UMM Press. 